\title{
CÓMO HACER COSAS CON ACCIONES (EN TORNO A LAS NORMAS DE ACCIÓN Y LAS NORMAS DE FIN)
}

Quisiera comenzar mi exposición con una advertencia: les advierto que corren el peligro de sentirse mortalmente aburridos dentro de escasos minutos. Temo que en estas páginas les voy a abrumar con una cantidad excesiva de matices y distinciones, acaso no muy acertadas. Mi única excusa, que me apresuro a ofrecer, es mi formación en lo que familiarmente llamamos la mayoría de los aquí presentes «filosofía analítica». La «filosofía analítica» me sigue pareciendo el método más fructífero en relación con los temas de los que nos ocupamos. Llegué al convencimiento de ello por dos vías: a través de las discusiones con mis compañeros de Alicante y con la lectura de los trabajos de Carlos Alchourrón y Eugenio Bulygin.

Sin embargo, si es cierto que a través de estos autores me introduje en el método analítico, hay algo que no he logrado aprender de ellos: me refiero a su habilidad para combinar de una manera tan notable la profundidad en el análisis con la claridad, la elegancia y la amenidad de la exposición. Si ellos hubieran escrito estas páginas, no sólo carecerían probablemente de errores, sino que, además, ustedes no se aburrirían tanto. Espero que Eugenio Bulygin, cuando compruebe lo fundado de mi advertencia inicial, me indique si existe alguna receta secreta, aunque mucho me temo que no exista tal cosa y que la única receta sea en realidad un intenso, serio y prolongado esfuerzo. Gracias a ese esfuerzo, la obra de «Carlos Eugenio Bulyrrón» se ha convertido en una de las más importantes de la filosofía del Derecho de los últimos años. Sus libros y artículos son el mejor ejemplo de la mejor aplicación del análisis lógico a la teoría de la norma y al Derecho.

En este trabajo voy a tratar de encontrar un resquicio donde «colarme» entre la obra de estos autores, por un lado, y la obra de Georg Henrik von Wright, por otro. Como saben ustedes, los trabajos de Alchourrón y Bulygin han introducido en la discusión de los filósofos del Derecho las investigaciones de von Wright sobre el concepto de norma y la lógica deóntica, y 
no es difícil advertir que la obra de Alchourrón y Bulygin y la de von Wright presenta una gran afinidad respecto a los métodos empleados y la selección de los temas. Sin embargo, existe una característica muy destacada en la obra de von Wright que no se encuentra en la de Alchourrón y Bulygin: me refiero a su insistencia en la dependencia entre el concepto de acción y el concepto de norma. Varios de los sistemas de lógica deóntica desarrollados por von Wright están basados en la lógica de la acción, lo que le ha llevado a analizar en profundidad esta noción. En cambio, en ninguna obra de Alchourrón y Bulygin se encuentra este interés por la teoría de la acción.

En Normative System, estos autores sostienen que el contenido de las normas es siempre una conducta o un estado de cosas resultado de una conducta ${ }^{1}$. En mi opinión, merece la pena profundizar en esta afirmación, porque podemos descubrir que, bajo una aparente uniformidad, los contenidos de las normas esconden distinciones que pueden ser relevantes. Permítanme comenzar este análisis con una historia, que nos servirá de ejemplo.

2. Supongamos que en un reino, el reino de Sollen, se alzan dos grandes templos, el Templo de Sein y el Templo de Tun, y que en cada templo hay una puerta sagrada que esconde graves misterios. Supongamos que cada una de estas puertas es custodiada por un guardián y que cada guardián se encuentra ante un muro de piedra en el que hay una palanca, un botón y una manivela. Todos estos instrumentos están conectados con la puerta sagrada de manera que al empujar la palanca hacia arriba ésta se cierra, y lo mismo ocurre si se presiona el botón o si (con algo más de esfuerzo) se dan varias vueltas a la manivela. No habría otra manera de cerrar las puertas, si éstas se abrieran. Sobre cada puerta hay una inscripción en letras rojas. Los templos, las puertas, el mecanismo de las puertas y hasta los dos guardianes se dirían idénticos, pero las inscripciones difieren sutilmente. Sobre la puerta del Templo de Sein la inscripción dice: «Es obligatorio que la puerta esté cerrada». Sobre la puerta del Templo de Tun la inscripción en cambio dice así: «Es obligatorio cerrar la puerta».

El guardián del Templo de Sein cumplía escrupulosamente su misión, no sólo cerrando la puerta cada vez que algo o alguien la abría, sino -más aún- tratando de evitar que algo o alguien la abriera, porque consideraba que éstas eran sus obligaciones. Pero aunque el mismo celo demostró el guardián del Templo de Tun, su actuación fue causa de terribles catástrofes y de una profunda conmoción en todo el reino, pues un día llegó un extranjero enmascarado y, ante los ojos impasibles del guardián, abrió la puerta.

\footnotetext{
${ }^{1}$ Carlos Alchourrón y Eugenio Bulygin, Introducción a la metodología de las ciencias jurídicas y sociales, Ed. Astrea, Buenos Aires, 1987, pág. 72.
} 
El guardián se limitó a cerrarla inmediatamente, pero el mal ya estaba hecho: tras la puerta del Templo de Tun estaban encerrados, como en la caja de Pandora, todos los vicios y defectos del mundo, muchos de los cuales escaparon y quedaron dispersos por el reino (qué esconde la puerta del Templo de Sein es aún objeto de controversia entre místicos y filósofos). El guardián del Templo de Tun se justificó diciendo que, a tenor de la inscripción, su única obligación era cerrar la puerta cada vez que algo o alguien la abriera, pero no impedir que algo o alguien la abriera. Los sacerdotes del templo, con el propósito sin esperanza de impedir que en un futuro escaparan los pocos vicios que aún el hombre no había saboreado, grabaron una nueva inscripción, que ahora decía: «Es obligatorio evitar que se abra la puerta, si está cerrada, y cerrarla, si está abierta».

3. Esta fantasía nos permite ilustrar la distinción que algunos autores trazan entre aquellas normas cuyo contenido -en el sentido de G.H. von Wright- es una acción y aquellas normas cuyo contenido es un estado de cosas. La formulación canónica de las primeras sería «Es obligatorio $p »$, donde $p$ es un verbo de acción en infinitivo, esto es, el nombre de una acción genérica o una clase de acciones; la formulación canónica de las segundas sería «Es obligatorio que $p$ », donde $p$ es un estado de cosas, o más exactamente una oración que describe un estado de cosas. Un ejemplo del primer tipo de normas sería «Es obligatorio cerrar la puerta»; un ejemplo del segundo tipo de normas sería «Es obligatorio que la puerta esté cerrada». A estos dos tipos de normas von Wright los llama, respectivamente, «normas de deber hacer» («tun-sollen norms») $\mathrm{y}$ «normas de deber ser» («sein-sollen norms») ${ }^{2}$. Aquí, siguiendo la terminología de Manuel Atienza y Juan Ruiz Manero, las llamaré reglas de acción y reglas de fin (o normas de acción y normas de fin, si se incluyen los principios).

Quizá convengan unas palabras sobre la historia de esta distinción: Su origen se puede situar en la construcción de los primeros sistemas de lógica deóntica, aunque pueden encontrarse referencias a las «normas de ser» en las Investigaciones filosóficas de Husserl ${ }^{3}$. Los sistemas que von Wright, Oscar Becker y George Kalinowski construyeron a comienzos de los años 50 consideraban que los operadores deónticos se aplicaban a acciones y no

${ }^{2}$ G.H. von Wright, «Problems and Prospects of Deontic Logic», en Modern Logic. A Survey, E. Agazzi (ed.) Dordrecht-Reidel, 1981, págs. 409 y ss.; G.H. von Wright, «Una introducción crítica», en Lógica deóntica, Cuadernos Teorema, Valencia, 1979, trad. de Jesús Rodríguez Marín; G.H. von Wright, Un ensayo de lógica modal y la teoría general de la acción, UNAM, México, trad. de Ernesto Garzón Valdés, 1976. Véase también Carlos Alchourrón, «G.H. von Wright y los desarrollos de la lógica deóntica», en Anuario de Filosofía Jurídica y Social, núm. 1, 1981, pág. 128 y ss.

\footnotetext{
${ }^{3}$ Jesús Rodríguez Marín, Lógica deóntica. Concepto y sistemas, Universidad de Valencia, 1978,pág.29.
} 
a estados de cosas, por lo que la lógica deóntica comenzó siendo una lógica de las normas de acción y no una lógica de las normas de fin. Pero al no existir una lógica de la acción, esto sólo permitía desarrollar sistemas muy pobres, que no podían dar cuenta de las normas de orden superior, como «Obligatorio permitido $p$ », ni de expresiones mixtas, como « $\mathrm{Si} p$ entonces obligatorio $q »$, pues resulta más correcto construir estas fórmulas si las variables expresan estados de cosas. Muchos autores optaron entonces por tratar a los contenidos de las normas como estados de cosas que deben ser el caso y, consiguientemente, a las variables del sistema como oraciones que expresan proposiciones sobre estados de cosas, y ya no como verbos de acción o acciones genéricas, avanzando así en la dirección de una lógica de las normas de fin. Esta ha sido la postura de lógicos como A.N. Prior y A.R. Anderson, y se ha extendido hasta el punto de que von Wright se lamentaba en un trabajo de 1981 de que «pocos estudiosos en este campo han prestado una atención especial a los problemas conectados con la lógica del deber hacer» ${ }^{4}$. En su opinión, la elección entre uno u otro tipo de lógica constituye un dilema, pues si bien la lógica de las normas de acción parece más rica e interesante, en ella se desvanece la analogía con la lógica modal alética, a diferencia de lo que ocurre con la lógica de las normas de fin. Ha habido, por cierto, intentos de reducir un tipo de lógica al otro, pero resultaron insatisfactorios ${ }^{5}$.

El mismo von Wright ha construido sistemas de lógica de uno u otro tipo de normas ${ }^{6}$. Además, en la clasificación de las normas que von Wright realiza

\footnotetext{
${ }^{4}$ Von Wright, «Problems and Prospects of Deontic Logic», pág. 410.
}

${ }^{5}$ Quienes se han ocupado de una lógica de las normas de fin han creído en ocasiones haber captado también las peculiaridades lógicas de las normas de acción: asumieron que la lógica de las normas de fin puede ampliarse hasta abarcar las normas de acción estipulando que sus variables pueden representar, además de proposiciones que describen estados de cosas, también proposiciones que describen la realización de un acción, aunque no verbos en infinitivo o clases de acciones. Pero este intento de reducir las normas de acción a normas de fin tropieza con una dificultad, pues no permite dar cuenta de la distinción entre no hacer y omitir. En palabras de ven Wright: «Si $p$ es una representación esquemática de una oración de acción (no de un verbo de acción), - $p$ representará la negación de esa oración. Pero la negación de una oración de acción debe ser distinguida de una oración al efecto de que cierta acción ha sido omitida. Por consiguiente, sólo a expensas de dejar a un lado la distinción entre no hacer y omitir se puede «transformar» una lógica del Deber-Hacer en una lógica del Deber-Ser por estipulación de que las variables de la lógica deóntica expresan oraciones de acción» (Von Wright, «Problems and Prospects of Deontie Logic», pág. $410)$.

${ }^{6}$ Así, en «Lógica deóntica» (Cuadernos Teorema, Valencia, 1979, trad. de Jesús Rodríguez Marín), en Norma y acción (ed. Tecnos, Madrid, trad. de Pedro García Ferrero, 1970), en «Nueva visita a la lógica deóntica» (en Lógica deóntica, Cuadernos Teorema, Valencia, 1979, trad. de Jesús Rodríguez Marín) y en «On the Logic of Norms and Action» (en Practical Reason, Philosophical Papers, vol. I. Basil Blackwell, 1983) encontramos sistemas de lógica de las normas de acción, mientras que en «A New System of Deontic Logic» (en R. Hilpinen, ed., 
en Norma y acción, este autor habla de reglas ideales, señalando que tienen relación «con cosas que deben, o pueden, o no tienen que ser» ${ }^{7}$. Creo que estas reglas serían un subgénero dentro del género de las normas de fin ${ }^{8}$.

Sin embargo, recientemente von Wright parece haber cambiado de opinión sobre esta distinción. En un libro reciente, Six Essays in Philosophical Logic, este autor incluye un artículo en el que, en lugar de admitir dos tipos de normas, sugiere que las normas prescriben aquello que debe ser, esto es, son siempre normas de fin, y de ellas se derivan para cada caso concreto reglas técnicas o "proposiciones de necesidad práctica», que expresan un deber hacer ${ }^{9}$. Escribe von Wright:

«Las normas prescriben en primer lugar lo que debe o puede ser hecho; las proposiciones de necesidad práctica establecen lo que el destinatario de las normas debe o puede hacer para cumplir sus obligaciones o aprovecharse de sus permisos» ${ }^{10}$.

La distinción entre uno u otro tipo de normas ya no depende de su contenido: aunque el contenido de las normas sea una acción, éstas serán normas de fin, dado que toda acción guarda una relación conceptual con el estado de cosas que constituye su resultado. Una norma como «es obligatorio cerrar la puerta» ahora es para von Wright una norma de fin. La distinción entre normas de fin y normas de acción se disuelve así en la distinción entre normas y reglas técnicas.

Fuera del ámbito de la discusión lógica, Manuel Atienza y Juan Ruiz Manero han defendido también esta misma distinción, conectándola con la noción de discrecionalidad. En Las piezas del Derecho escriben lo siguiente:

«(...) debe advertirse que el ver el consecuente (la solución) de las normas en términos de calificación normativa de una determinada conducta es sólo adecuado

Deontic Logic: Introductory and Sistematic Readings, 1971) y en «Deontic Logic and the Theory of Conditions» (Crítica, vol, II, núm. 6, México, 1968) encontrarnos sistemas de lógica de las normas de fin. En uno de sus últimos trabajos sobre lógica deóntica, Norms, Truth and Logic (Practical Reason, Philosophical Papers, vol, I. Basil Blackwell, 1983), presenta dos simbolismos para un mismo sistema, permitiendo una interpretación del sistema como una lógica de normas de acción y otra como una lógica de las normas de fin.

${ }^{7}$ Von Wright, Norma y acción, pág. 33.

${ }^{8}$ Aunque todas las reglas ideales son reglas de fin, no todas las reglas de fin son reglas ideales. Las reglas ideales tienen un matiz que las asemeja a las reglas definitorias: definen cómo debe ser un «lo que sea» ideal. En cambio, no puede decirse lo mismo de muchas reglas de fin. Una norma que diga que «es obligatorio que la puerta esté cerrada» es una regla de fin, pero es absurdo pensar que hay algo así como una puerta ideal que se define -entre otras cosas- por estar cerrada. Las reglas de fin, en cambio, sí hacen referencia a cuál es el «mundo ideal» o el estado de cosas ideal en relación con la puerta de que se trate: estar cerrada.

${ }^{9}$ G.H. von Wright, «Ought to be - Ougth to do», Six Essays in Philosophical Logic, Acta Philosophica Fennica, Helsinki, 1996, págs. 63-70. 
para el tipo más común de reglas jurídicas de mandato, a las que proponemos llamar reglas de acción. Junto a ellas, los sistemas jurídicos contienen también reglas que califican deónticamente no una determinada conducta, sino la obtención de un cierto estado de cosas. Proponemos denominar a las reglas de mandato de este último tipo reglas de fin. La diferencia entre las reglas de acción y las reglas de fin es relevante en ocasiones, si bien en otras puede tratarse de una mera cuestión de estilo legislativo. Así, por ejemplo, tanto da que -a no ser que concurra una causa de justificación- se prohíba la acción de matar como que se prohíba el estado de cosas consistente en haber producido la muerte: en este sentido, cualquier regla formulada en términos de regla de acción es «traducible» a términos de regla de fin (y una y otra no son más que dos formas de decir lo mismo). Pero la distinción es relevante cuando la disposición que estipula como obligatoria, por ejemplo, la producción de un determinado estado de cosas deja a la discreción de su destinatario la selección de los medios causalmente idóneos para producirlo: en este sentido, las reglas de fin dejan a sus destinatarios un margen de discreción que no existe en el caso de las reglas de acción» ${ }^{11}$.. Von Wright escribió en cierta ocasión que la posibilidad de transformación de las normas de un tipo en normas del otro es un problema lógico-filosófico abierto ${ }^{12}$. En las páginas que siguen quiero volver a este problema abierto, indagando en ambos tipos de normas, analizando la posibilidad de «traducción» de un tipo al otro y profundizando en la sugerencia de Atienza y Ruiz Manero de que esta distinción tiene relación con la noción de discrecionalidad ${ }^{13}$.

${ }^{11}$ Manuel Atienza y Juan Ruiz Manero, Las piezas del Derecho. Ariel, Barcelona, 1996, pág. 8. Nótese que la terminología usada por estos autores para trazar la distinción puede dar lugar a equívocos: para ellos una regla de fin es la que califica deónticamente «la obtención de un cierto estado de cosas», mientras que las reglas de acción califican deónticamente una conducta o acción. Pero podría pensarse que las acciones consisten también en obtener un estado de cosas (von Wright. Norma y acción, pág. 53), con lo que la diferencia entre ambos tipos de normas, así trazada, se desdibuja. Por otro lado, en Las piezas del Derecho, Atienza y Ruiz Manero trazan una distinción paralela entre reglas de acción y reglas de fin en el nivel de los principios: los principios en sentido estricto y las directrices.

12 «Una introducción crítica», en «Lógica deóntica», pág. 19.

${ }^{13}$ En realidad, me parece que el párrafo de Las piezas del Derecho donde sus autores trazan la distinción entre reglas de acción y reglas de fin puede interpretarse de tres maneras distintas: (1) Si lo que Atienza y Ruiz Manero están afirmando es que, debido a ciertas peculiaridades estructurales (califican deónticamente la obtención de un estado de cosas» y no una conducta), las normas de fin, a diferencia de las normas de acción, dotan de discrecionalidad al destinatario de la norma, entonces mi postura sería la de tratar de mostrar que también algunas normas de acción dotan de discrecionalidad. (2) Si su postura es que las normas de fin se definen como aquellas que dotan de discrecionalidad al destinatario de las normas, la relación entre normas de fin y discrecionalidad se vuelve analítica y no tengo nada que decir sobre ella, al margen de conveniencias terminológicas. (3) Si su postura es que la distinción entre normas de fin y normas de acción sólo es relevante en aquellos casos en que las normas de fin permiten dotar al destinatario de discrecionalidad mientras que las normas de acción no lo permiten (porque en estos casos no son traducibles unas a otras), entonces estoy completamente de acuerdo con ellos. 
Comencemos por el principio, esto es, por el concepto de acción.

4. En realidad es un principio demasiado ambicioso, porque dar una noción de acción que abarque todos los supuestos que llamamos acciones (acciones naturales, acciones institucionales, acciones mentales, acciones intencionales, actos reflejos, etc.) es una empresa sencillamente ingente. Nos ha de bastar con una noción que sirva para algunos casos que sean centrales. Con esta advertencia, podemos decir, con palabras de von Wright, que «muchos actos pueden describirse adecuadamente como el provocar o efectuar("a voluntad") un cambio», entendiendo que un cambio es el paso de un estado de cosas a otro estado de $\operatorname{cosas}^{14}$. Que la puerta se ha abierto o se ha cerrado es un suceso o cambio, algo que ha ocurrido en el mundo; que el guardián del templo cierra la puerta es una acción, consistente en producir el cambio de que la puerta pase de estar abierta a estar cerrada.

Pero esta caracterización de las acciones es todavía demasiado vaga y no toma partido por una alternativa conceptual con la que inevitablemente acaba tropezando el teórico de la acción: Algunos autores, como Donald Davidson y Elizabeth Anscombe, sostienen que las acciones son secuencias de movimientos corporales que pueden interpretarse de una $u$ otra manera $^{15}$; frente a esta postura, se puede sostener que las acciones son movimientos corporales ya interpretados o descritos de cierta manera. Una analogía con el concepto de norma puede aclarar esta noción de acción, que es la que voy a asumir aquí: desde una postura sintáctica, a veces se identifica a las normas con los enunciados normativos (la «formulación normativa»); desde una postura semántica, se las identifica con el significado de los enunciados normativos; y desde una postura mixta, Alchourrón y Bulygin han propuesto una noción según la cual las normas no son enunciados sin más y tampoco significados sin más, sino «oraciones significativas, esto es, oraciones dotadas de un significado definido y constante ${ }^{16}$. De la misma manera podría decirse que una acción no es ni una mera secuencia de movimientos corporales ni una descripción de movimientos corporales, sino movimientos corporales con un sentido definido y constante. De acuerdo con esta caracterización de las acciones, la descripción o interpretación, esto es, el sentido que le atribuimos a los movimientos corporales, es un elemento intrínseco de la acción.

\footnotetext{
${ }^{14}$ G. H, von Wright, Norma y acción, pág. 43 y ss.

${ }^{15}$ Véase, por ejemplo, Donald Davidson, «De la acción», en Ensayos sobre acciones y sucesos, UNAM-Crítica, 1995, trad. de Olbeth Hansberg, José Antonio Robles y Margarita Valdés.

${ }^{16}$ Eugenio Bulygin, «Dogmática jurídica y sistematización del Derecho», en Análisis lógico y Derecho, Centro de Estudios Constitucionales, Madrid, 1991, pág. 468. Carlos Alchourrón, «Systematization and Change in the Science of Law», Rechtstheorie, núm. 10, 1986, pág. 173.
} 
Ahora bien, ¿de qué depende tal interpretación? Me parece que la respuesta es la siguiente: Un movimiento corporal suele provocar una cadena de cambios (por ejemplo, cuando en 1914 Gavrilo Princip apretó el gatillo de su arma en Sarajevo, también disparó la pistola, mató al archiduque Francisco Fernando, asestó un golpe a Austria, vengó a Serbia y fue el detonante de la Primera Guerra Mundial). Al interpretar los movimientos corporales seleccionamos uno de esos cambios y lo utilizamos para individualizar y dar nombre a la acción. Esta selección la realizamos guiados por ciertos criterios que constituyen algo así como «la gramática del actuar», como son la intención del agente, la longitud de la cadena causal, la relevancia social del cambio, etc. ${ }^{17}$. De forma que si una acción es un movimiento corporal interpretado de una determinada manera en función de un cambio, entonces tal cambio también es un elemento intrínseco de la acción: en palabras de von Wright, éste es el resultado de la acción. La diferencia radica en que von Wright parece reducir los criterios para seleccionar un cambio como el resultado de una acción a la intención del agente ${ }^{18}$.

Avancemos más en nuestro análisis.

5. Una de las preguntas sobre las acciones que más atención ha recibido por parte de los filósofos de la acción es «¿por qué x hizo tal cosa?». Esta pregunta abre un mundo de razones, motivos, deseos e intenciones ante nosotros. Sin embargo, aquí voy a optar por una pregunta distinta y me temo que bastante más olvidada por los filósofos, con la salvedad de John Austin respecto a los actos de habla ${ }^{19}:$ «¿cómo hizo x tal cosa?». ¿Cómo ha producido el guardián de nuestra historia el cambio consistente en que la puerta se cerrara? No podemos contestar esta pregunta diciendo simplemente que lo ha hecho cerrando la puerta, esto es, con la acción de cerrar la puerta, porque lo que en realidad estamos preguntando es precisamente cómo ha realizado esta acción. Una respuesta más adecuada sería, siguiendo con nuestro ejemplo, decir que lo ha hecho presionando el botón, o empujando la palanca, o dando vueltas a la manivela. Esto es, debemos señalar alguna otra acción que guarda una relación especial con la acción por la que estamos preguntando. Desde esta perspectiva, realizar una acción consiste en realizar otra acción que genera la primera acción. La pregunta «¿cómo hacemos acciones?» puede responderse diciendo que hacemos acciones con acciones, salvo en un caso: Este proceso tiene como límite las acciones que consisten exclusivamente en movimientos corporales o acciones básicas, que

${ }^{17}$ Ricardo Guibourg, El fenómeno normativo, Ed. Astrea, Buenos Aires, 1987, pág. 52.

${ }^{18}$ G.H. von Wright, Norma y acción, pág. 58. Daniel González Lagier, Acción y norma en G.H. von Wright, Centro de Estudios Constitucionales, Madrid, 1995, pág. 68 y 96 y ss.

19 John L. Austin, Como hacer cosas con palabras, Ed. Paidós, Buenos Aires, 1988, trad. de Genaro R. Carrió y Eduardo Rabossi. 
son aquellas que hacemos directamente ${ }^{20}$. Esto es lo que permite a autores como Feinberg distinguir entre actos simples y actos complejos: los primeros son aquéllos que no requieren que hagamos algo más (como levantar un brazo o flexionar un dedo); los segundos requieren que, como un medio, hagamos primero algo más (como abrir una puerta o matar a alguien) ${ }^{21}$. Estoy convencido de que ustedes estarán esperando que les diga cómo hacemos aquellas acciones que no hacemos con otras acciones. Me temo que voy a defraudarles: no lo sé; mi única excusa es que la respuesta, o bien no es filosófica (al menos en el sentido moderno de «filosofía»), sino que debe provenir de otras ramas del conocimiento, como la neurología, o bien es demasiado filosófica para que yo aspire a encontrarla, porque se relaciona con el viejo problema de la conexión mente-cuerpo.

Por otro lado, soy consciente también de que la relación de generación entre acciones es oscura y controvertida, pero no puedo detenerme en ella ${ }^{22}$. Me limitaré a dos consideraciones:

En primer lugar, hemos visto que una misma secuencia de movimientos corporales puede dar lugar a una cadena más o menos larga de cambios en el mundo, por lo que la interpretación o descripción de esos movimientos corporales puede variar de acuerdo con el cambio al que prestemos atención. Así, en nuestro ejemplo, los mismos movimientos corporales que pueden describirse como «presionar el botón», pueden describirse también como «cerrar la puerta». Dado que para nosotros una acción no es un mero movimiento corporal, sino una combinación de un movimiento corporal y una interpretación del mismo, en la medida en que un mismo movimiento corporal sea interpretado de varias maneras, pertenecerá a acciones distintas. Es entre estas acciones que «comparten», por decirlo así, un mismo movimiento corporal donde surge una relación de generación.

En segundo lugar, la relación de generación puede ser al menos de dos tipos: causal, como la relación entre disparar un arma y matar, o convencional (en un sentido amplio del término), como la relación entre decir «Yo prometo» y estar asumiendo una obligación, o entre mover la reina y hacer jaque mate.

Volvamos ahora a la pregunta «¿cómo ha hecho el guardián para cerrar la puerta?». En nuestro ejemplo había tres maneras de cerrar la puerta: presionar

\footnotetext{
${ }^{20}$ Aunque algunos autores han negado que las acciones básicas sean los movimientos corporales, y han dado este carácter a las intenciones, al intentar hacer algo, etc. Véase Carlos J. Moya, The Philosophy of Action. An Introduction, Polity Press, 1990, pág. 17 y capítulo 2.

${ }^{21}$ Joel Feinberg, «Action and responsibility», en A.R. White, The Philosophy of Action, Oxford University Press, 1968, págs. 95-119.

${ }^{22}$ Sobre el concepto y los tipos de generación entre acciones puede verse Alvin I. Goldman, A Theory of Human Action, capítulo 2, «The Structure of Action», Priceton University Press, 1970.
} 
el botón, empujar la palanca y mover la manivela. Supongamos que el guardián ha presionado el botón. Entonces podemos contestar satisfactoriamente la pregunta diciendo que el guardián ha cerrado la puerta presionando el botón, o que ha cerrado la puerta al presionar el botón. En ambos casos, la acción que hemos introducido (presionar el botón) indica cómo se ha realizado la acción por la que preguntábamos.

Tenemos ahora dos acciones distintas -la acción por la que preguntamos y la acción con la que respondemos- que apuntan a dos tipos distintos de acción, así que deberíamos acuñar nombres distintos para estos tipos. A la acción por la que estamos preguntando la llamaré «acción final»; a la acción con la que indicamos cómo se ha hecho la acción final la llamaré «forma» de la acción final. Por supuesto, esta distinción es relativa a un observador (que podría ser incluso el propio agente): El observador pregunta cómo se ha realizado una acción (o cómo se ha producido el cambio que da nombre a esa acción); ésta es entonces la acción final. Le contestamos haciendo referencia a otra acción; ésta es la forma de la acción final.

6. Pero llegados a este punto podríamos preguntarnos lo siguiente: ¿no cabría dar una respuesta distinta -más detallada- a la pregunta acerca de cómo ha cerrado el guardián la puerta? Quizá podríamos decir: Pues bien, el botón está en lo alto del muro, así que el guardián ha tenido que subir unos escalones, después se ha quitado los guantes, porque éstos volvían torpes sus movimientos, ha acercado su mano derecha al botón, ha apoyado el dedo índice sobre el mismo y lo ha empujado hacia adelante. Esta podría ser una respuesta satisfactoria. E incluso podríamos hacer una descripción todavía más cercana a meros movimientos corporales del guardián, aunque esto resultaría extraño -a veces, ridículo ${ }^{23}$, , creando un efecto semejante a las «Instrucciones para subir una escalera» de Julio Cortázar:

«Las escaleras se suben de frente -nos instruye Julio Cortázar-, pues hacia atrás o de costado resultan particularmente incómodas. La actitud natural consiste en mantenerse de pie, los brazos colgando sin esfuerzo, la cabeza erguida aunque no tanto que los ojos dejen de ver los peldaños inmediatamente superiores al que se pisa, respirando lenta y pausadamente. Para subir una escalera se comienza por levantar esa parte del cuerpo situada a la derecha abajo, envuelta casi siempre en cuero o gamuza, y que salvo excepciones cabe exactamente en el escalón. Puesta en el primer peldaño dicha parte, que para abreviar llamaremos pie, se recoge la parte equivalente de la izquierda (también llamada pie, pero que no ha de confundirse con el pie antes citado) y llevándola a la altura del pie, se la hace seguir hasta colocarla en el segundo peldaño, con lo cual en éste descansará el pie, y en el primero descansará el pie».

${ }^{23}$ Salvo en procesos de aprendizaje e instrucción, en casos de ejercicios terapéuticos o de entrenamiento deportivo, en clases de canto o de idiomas, etc. no nos fijamos mucho en los movimientos corporales necesarios para realizar una acción. 
¿Qué relación guarda cada una de estas acciones -subir los escalones, quitarse los guantes, etc.- con la acción de «cerrar la puerta»? Parece claro que también existe aquí una relación condicional. Dado el contexto descrito, subir las escaleras, quitarse los guantes, etc. son acciones que el guardián ha hecho para presionar el botón y, de esta manera, cerrar la puerta. Sin embargo hay una diferencia importante entre estas acciones y las que hemos llamado «formas» de la acción. Esta diferencia se manifiesta en dos circunstancias: La primera, que la referencia a una de estas acciones, al contrario de lo que ocurre con las formas de la acción, no es una respuesta satisfactoria a la pregunta «¿cómo ha cerrado el guardián la puerta?». Si nos hacen esta pregunta, no podemos contestar diciendo «El guardián ha cerrado la puerta quitándose los guantes», o «El guardián ha cerrado la puerta al quitarse los guantes», porque ésta es una respuesta incompleta o significa algo totalmente distinto ${ }^{24}$. La segunda, que la relación entre estas acciones y la acción final no es una relación directa, sino que pasa a través de las formas de la acción. A estas acciones que guardan una relación condicional no directa con la acción por la que preguntamos y no ofrecen respuestas completas las llamaré fases de la acción final.

Por tanto, las acciones -salvo las acciones simples o básicas- son el producto de otras acciones. Algunas de éstas son fases en relación con la acción final, otras son formas en relación con la acción final.

Trataré ahora de trazar con mayor precisión la distinción entre fases y formas de la acción.

7. Donald Davidson ha escrito que «Nunca hacemos más que mover nuestros cuerpos; lo demás se lo dejamos a la naturaleza ${ }^{25}$. Con esta frase, Davidson pretende identificar a las acciones con los movimientos corporales, pero aun con nuestra noción de acción como movimientos corporales interpretados la frase sigue teniendo mucho de verdad. El éxito en cualquiera de nuestras acciones -salvo quizá las acciones simples- nunca depende por entero de nosotros. Quizá sólo depende de nosotros en una medida muy pequeña. Esto es cierto incluso para las acciones generadas convencionalmente,

\footnotetext{
${ }^{24}$ Parece que estuviéramos indicando «cuándo» (y no «cómo») ha presionado el botón. Sin embargo, también puede significar -lo que es más interesante- algo así como: «El guardián ha cerrado la puerta (involuntariamente) cuando se quitaba los guantes» (por ejemplo, porque al quitarse los guantes ha accionado el botón o la palanca inadvertidamente). Aquí de nuevo se introduce un circunstancial de modo, sugiriéndose que la acción fue involuntaria o accidental, ya que quitarse los guantes no es normalmente una manera adecuada de cerrar una puerta, esto es, no es la manera que el agente habría escogido si hubiera querido cerrar la puerta. Esto conecta con la tesis de algunos autores de que la adecuación o no del medio elegido para realizar una acción es un indicador de si la acción fue voluntaria o involuntaria (véase Carlos S. Nino, Introducción a la filosofia de la acción humana, Eudeba, Buenos Aires, 1987. pág. 39).
}

${ }^{25}$ Donald Davidson, «De la acción», en Ensayos sobre acciones y sucesos, pág. 82. 
porque en éstas también aparecen tramos causales: por ejemplo, en una determinada posición de las fichas, para hacer jaque mate debemos mover la reina, pero el movimiento de la reina a una determinada casilla depende de factores causales.

Que el éxito de nuestras acciones nunca dependa por entero de nosotros se puede explicar recurriendo a la noción de contexto causal. Estrictamente hablando, un suceso nunca es producido únicamente por lo que llamamos su causa. Para que ocurra un suceso es necesario que se produzca una conjunción de condiciones tal que todas ellas, consideradas globalmente, sean condición suficiente del suceso. Así, para que se produzca un incendio no basta con que alguien encienda un fósforo y lo arroje al bosque: es necesario además la presencia del oxígeno en el aire, que el nivel de humedad no supere cierto límite, etc. La causa del suceso es sólo un elemento que individualizamos porque es un elemento extraño, anormal, en el contexto ${ }^{26}$. De manera que cuando actuamos tratamos de ser o de provocar el elemento diferencial que cierra un contexto causal y produce un cambio. Por ello, cualquier acción requiere en última instancia la intervención de la naturaleza, y siempre es posible que suceda algún imprevisto.

Y sin embargo, siendo cierto lo anterior, estamos seguros -razonablemente seguros- de que podemos abrir una puerta, cerrar una ventana, levantarnos cada mañana, encender la luz, preparar una tostada y desplazarnos en coche hasta nuestro trabajo. Todas las acciones (salvo las acciones simples) requieren acciones preparatorias, que van cerrando el contexto causal, pero inevitablemente llega un momento en que ya no podemos hacer más, sólo esperar y confiar en nuestro éxito. El guardián de nuestro ejemplo presionó el botón (para ello tuvo que hacer otras cosas), y una vez hecho esto sólo cabía esperar que la puerta se cerrara. Una vez presionado el botón, lo demás no le correspondía. Lo mismo podemos decir si ha empujado la palanca o si ha dado varias vueltas a la manivela, pero no si sólo ha subido los escalones o se ha quitado los guantes. Tras subir los escalones y quitarse los guantes, todavía le quedan algunas cosas por hacer antes de cerrar la puerta.

Teniendo en cuenta estas observaciones, podríamos decir que presionar el botón, empujar la palanca y dar vueltas a la manivela pueden considerarse condiciones razonablemente suficientes (cada una de ellas) de la acción de cerrar la puerta. Un lógico puede encontrar desconcertante que se hable de condiciones razonablemente suficientes, pero me temo que es un concepto con el que debemos contar en teoría de la acción, al menos por dos razones: la primera, el carácter inductivo de nuestro conocimiento de las relaciones

${ }^{26}$ Ernest Nagel, La estructura de la ciencia, Ed. Paidós, Buenos Aires, 1981, pág. 80. 
causales; la segunda, el hecho de que nunca podemos estar absolutamente seguros de que el contexto causal en un determinado momento sea exactamente el adecuado para producir el cambio que pretendemos, porque sus variables escapan a nuestra capacidad de análisis. Por otro lado, quitarse los guantes o subir los escalones son condiciones preparatorias de «cerrar la puerta», pero no son condiciones razonablemente suficientes de ello ${ }^{27}$. relaciones ${ }^{28}$ :

En el siguiente cuadro trato de resumir las nociones de forma y fase de la acción y sus

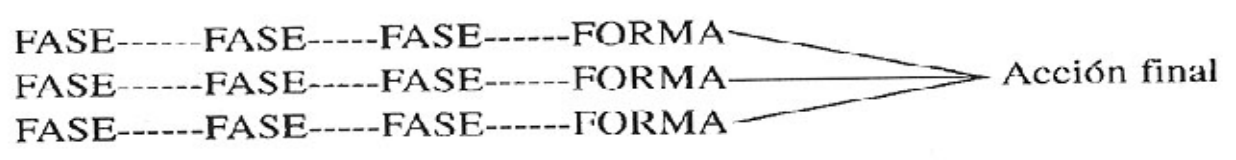

Para terminar con la noción de forma de la acción, tres consideraciones más:

La primera es que, en nuestro ejemplo, cerrar la puerta es una acción que puede realizarse de tres formas distintas. Pero existen acciones que pueden realizarse de incontables (aunque no infinitas) formas distintas y acciones que sólo pueden realizarse de una forma. Las formas de una acción dependen de cuestiones lógicas o conceptuales (por ejemplo, abrir una puerta nunca puede ser una forma de cerrar esa misma puerta), fácticas (relaciones causales, capacidad humana,...) y (si nos referimos a acciones individuales y no a acciones genéricas) contextuales.

La segunda consideración es la siguiente: Debe observarse que lo que llamo forma de la acción no es simplemente la conjunción de las fases de la acción. No basta con realizar todas las fases de una acción para generar esa acción: realizar todas las fases es la parte que nos corresponde a nosotros, pero después debemos esperar la «ayuda» de la naturaleza para que realmente tenga lugar el cambio que deseamos. Si ese cambio no se produce, no hemos logrado generar la nueva acción.

Y la tercera consideración es la siguiente: He caracterizado las formas de la acción en términos condicionales causales o convencionales. Se trata de acciones que constituyen condiciones razonablemente suficientes de otras acciones. Sin embargo, llamarlas «formas» de una acción parece sugerir

27 Por condición preparatoria entiendo condición necesaria, pero no suficiente, o condición meramente contribuyente. Obsérvese que las fases tampoco pueden ser condiciones suficientes de la forma de la acción, porque en ese caso serían también condiciones suficientes de la acción final y, por tanto, formas de ésta.

${ }^{28}$ Cada forma de la acción es condición suficiente de la acción final, y su disyunción es condición necesaria de la misma. Cada fase de la acción es condición preparatoria de la acción final. En relación con la forma correspondiente son condiciones necesarias o meramente contribuyentes. 
alguna conexión de otra índole, quizá por las resonancias aristotélicas de la expresión. La relación entre forma y acción recuerda a la relación entre forma y materia. De la misma manera que la materia debe adoptar una determinada forma, la acción debe manifestarse en alguna de sus formas. Es difícil determinar si esta relación es un tipo específico y peculiar o si es una relación de género a especie, o meramente causal, o conceptual, o de algún otro tipo. No me siento capaz de decantarme ahora por una respuesta, pero sí voy a hacer la siguiente observación: el hecho de que yo haya caracterizado la relación en términos condicionales no excluye que desde otra perspectiva la relación aparezca con un carácter distinto ${ }^{29}$. Lo que quiero decir es que el tipo de relación que existe entre dos elementos puede variar de acuerdo con la perspectiva que adoptemos. Un ejemplo de Ernest Nagel puede servir para ilustrar este punto:

«Hubo una época -escribe este autor-, en la cual se identificaba el cobre mediante propiedades entre las que no figuraba ninguna de las propiedades eléctricas de esta sustancia. Después del descubrimiento de la electricidad se afirmó, sobre bases experimentales, que la oración «el cobre es un buen conductor de la electricidad» es una ley de la naturaleza. Con el tiempo, sin embargo, la alta conductividad fue incluida en las propiedades definitorias del cobre, de modo que la oración «el cobre es un buen conductor de la electricidad» adquirió un nuevo uso y un nuevo significado. En su nuevo uso, la oración ya no expresó simplemente una verdad lógicamente contingente como antes, sino que sirvió para enunciar una verdad lógicamente necesaria» ${ }^{30}$.

Trasladando esto a nuestra distinción podemos decir que, si nos parece que existe alguna conexión lógica, o conceptual, o de género a especie, entre las formas de una acción y la acción correspondiente, ésta relación se apoyaría en una abstracción del hecho de que las formas de una acción son causal o convencionalmente medios adecuados para generar esa acción.

8. Ya estamos suficientemente pertrechados para volver a la distinción entre normas de acción y normas de fin, de la que a estas alturas pensarán ustedes que me he olvidado. Hemos encontrado que, a pesar de la aparente homogeneidad del contenido de las normas, algunas pueden referirse a estados de cosas y otras a acciones. Y si nos fijamos sólo en aquéllas cuyo contenido es una acción, todavía tenemos que distinguir si se trata de una acción final, de una forma de acción o de una fase de acción. De manera que hay que tener en cuenta esta diversidad dentro de las normas de acción para establecer el alcance de la distinción entre normas de fin y normas de acción.

${ }^{29}$ Por ejemplo, desde una perspectiva posterior a la acción, o si nos referimos a acciones genéricas, podemos decidir no tener en cuenta las conexiones causales, en cuyo caso la relación entre forma y acción final no se vería como una relación causal.

${ }^{30}$ Ernest Nagel, La estructura de la ciencia, pág. 62. 
Volvamos a nuestro ejemplo: Como sugería con la historia del comienzo, la norma «Es obligatorio que la puerta esté cerrada» es una norma de fin que puede traducirse en la doble norma de acción «Es obligatorio evitar (o impedir) que se abra la puerta, si está cerrada, y es obligatorio cerrarla, si está abierta» ${ }^{31}$. Para que la «traducción» de una norma de fin a una norma de acción sea correcta ambas normas deben ser equivalentes (entendiendo que dos normas son equivalentes cuando las obligaciones que se derivan de ellas son las mismas para los mismos individuos ${ }^{32}$ ); para ello se han de tener en cuenta ciertos requisitos, entre los que cabe destacar los siguientes:

(1) Una norma de fin debe traducirse, al menos, en una conjunción de dos normas de acción con condiciones de aplicación distintas: una norma que obligue a impedir un cambio (por ejemplo, que se abra la puerta) y una norma -cuya condición de aplicación requiere la violación de la primera que obligue a restablecer la situación inicial (cerrar la puerta).

(2) Las normas de fin deben traducirse a normas de acción cuyo contenido es una acción final (o bien una disyunción de todas las formas de acción de esa acción final). En nuestro ejemplo, la norma «Es obligatorio que la puerta esté cerrada» no es equivalente a una norma que dijera «Es obligatorio presionar el botón», pero sí -prescindiendo del anterior requisito- a una norma que dijera «Es obligatorio cerrar la puerta» o una que dijera «Es obligatorio presionar el botón o empujar la palanca hacia arriba o dar varias vueltas a la manivela».

De todo esto parecería deducirse que todas las normas de fin pueden traducirse a normas de acción. Si esto fuera así, los únicos motivos -aunque no desdeñables- que tendría la autoridad para utilizar un tipo u otro de norma serían de índole práctica o estilística (parece más engorroso el recurso a normas de acción). Sin embargo, hay algunas consideraciones más que hacer, relacionadas con la noción de discrecionalidad y con el tipo de cambios que tiene sentido regular por medio de normas.

9. Vayamos primero con la noción de discrecionalidad. Supongamos que uno de los guardianes de nuestro ejemplo es el destinatario de una norma que dijera: «Es obligatorio empujar la palanca, cuando la puerta está abierta». Nuestro guardián sabe que cuando se empuja la palanca la puerta se cierra; sabe asimismo que la puerta se cierra también cuando se presiona el botón y cuando se gira la manivela. Sin embargo, estas dos últimas posibilidades no son alternativas que él deba tener en cuenta. Se trata de un supuesto

${ }^{31}$ Asumo que una acción, en realidad, puede consistir tanto en producir cambios como en evitar que sucedan. Véase Von Wright, Norma y acción, pág. 46 y ss.

${ }^{32}$ Para simplificar, dejo de lado consideraciones relativas a la ocasión y las condiciones de aplicación de las normas. 
en el que, auque existen diversas formas de la acción, no existe discrecionalidad.

Se da un caso de discrecionalidad, por tanto, cuando existen varias formas de una acción y al destinatario de la norma le está permitido escoger entre varias de ellas. Supongamos que nos interesa dotar a un agente de la máxima discrecionalidad posible respecto a un caso. Una manera de hacerlo podría ser la de dictar una norma cuyo contenido fuera una disyunción de todas las formas de una acción. Pero dado que para la mayoría de los casos puede resultar imposible enumerar todas las formas de la acción, la autoridad puede simplemente dictar una norma cuyo contenido sea la acción final o una norma de fin. «Es obligatorio impedir que la puerta se abra y cerrarla si se abre» y «Es obligatorio que la puerta esté cerrada» dotan de idéntica discrecionalidad a los guardianes de las puertas del Templo de Tun y el Templo de Sein. En cambio, si la norma dice «Es obligatorio presionar el botón», la discrecionalidad desaparece.

A la luz de estas observaciones parece que las normas de acción cuyo contenido es una acción final y las normas de fin son medios igualmente idóneos (con las salvedades prácticas y estilísticas mencionadas) para dotar de discrecionalidad al destinatario de las normas. Esta discrecionalidad disminuye en relación con las normas cuyo contenido es una o varias formas (pero no todas) de la acción y aquellas cuyo contenido es una o varias fases (pero no todas) de la acción. La relevancia de la distinción entre normas de fin y normas de acción final dependerá entonces de si hay normas que califican deónticamente cambios o estados de cosas que no pueden ser el resultado de una acción.

10. Vayamos ahora con los tipos de cambios que tiene sentido regular mediante normas. Tradicionalmente el principio «Debe entraña puede» se ha interpretado diciendo que sólo tiene sentido dictar normas sobre aquellos cambios que no son ni necesarios ni imposibles. Esto es, sólo respecto a aquellos cambios a los que podemos dar lugar. Pero la expresión «poder dar lugar» es demasiado vaga. En primer lugar, podemos preguntarnos si nos referimos a un agente concreto en una ocasión determinada, a un agente concreto en cualquier ocasión, al conjunto de todos los agentes en una ocasión determinada o al conjunto de todos los agentes en cualquier ocasión. Aquí me referiré a esta última noción, más genérica, de «poder». En segundo lugar, cabe preguntarse si el «poder» se refiere a una posibilidad lógica, a una posibilidad empírica o a una posibilidad técnica (algo puede ser empíricamente posible, pero técnicamente imposible). Me referiré a este tercer sentido de «poder», que incluye los demás. En tercer lugar, la distinción entre lo posible y lo imposible es demasiado tajante. En su lugar, propongo que distingamos entre cambios (razonablemente) dentro del control del agente 
(como cerrar una puerta), cambios fuera del control del agente (como provocar que llueva mañana) y cambios parcialmente dentro (o fuera) del control del agente (como hacer que aumente la esperanza de vida o sacar un doce con los dados). Un cambio está dentro del control de un agente cuando puede realizarse una acción que constituye una condición razonablemente suficiente del cambio. Un cambio está totalmente fuera del control del agente cuando no puede realizarse ni una condición suficiente ni siquiera una condición preparatoria de ese cambio. Y un cambio está parcialmente dentro del control del agente cuando sólo pueden realizarse condiciones preparatorias del cambio, pero no condiciones suficientes del mismo.

Sobre este tipo intermedio de cambios nos podemos preguntar dos cosas: La primera, si el principio «debe entraña puede» se refiere también a ellos, o si sólo se refiere a un sentido fuerte de «poder» (esto es, a los cambios totalmente dentro del control). La segunda, si dar lugar a un cambio parcialmente dentro del control del agente es una acción (o el resultado de una acción), o sólo consecuencia en última instancia de nuestros movimientos corporales, pero fuera del ámbito de lo que llamamos acciones.

Vayamos con la primera cuestión. ¿Tiene sentido dictar normas sobre cambios parcialmente dentro del control del agente? En mi opinión no sólo tiene sentido, sino que de hecho podemos encontrar muchos ejemplos (como la mayoría de las normas programáticas de nuestras Constituciones). Una norma que tenga como contenido un cambio parcialmente dentro del control del agente cumple una doble función: por un lado, presenta ese cambio como un objetivo dotado de valor; por otro lado, prescribe realizar las acciones que posibilitan (aunque no aseguran) ese objetivo ${ }^{33}$. Las normas que Manuel Atienza y Juan Ruiz Manero llaman directrices, que se caracterizan por obligar a alcanzar un determinado estado de cosas en la mayor medida posible, podrían verse como ejemplos de este tipo ${ }^{34}$.

Vayamos ahora con la segunda cuestión. ¿Dar lugar a un cambio parcialmente dentro del control del agente es una acción o sólo algo que hacemos a través de acciones? ¿Existe una acción de «aumentar el nivel de vida», o de «sacar doce a los dados»? En mi opinión, una respuesta afirmativa resultaría distorsionadora. Me parece más correcto decir que éstas son cosas que hacemos con nuestras acciones, pero no son acciones nuestras. Lo que quiero sugerir es que entre los criterios que usamos más o menos inconscientemente para seleccionar el cambio que constituye el resultado de nuestras acciones, lo que he llamado «la gramática del actuar», encontramos

\footnotetext{
${ }^{33}$ De esta manera, estas normas reunirían las dos dimensiones que según Manuel Atienza y Juan Ruiz Manero tienen todas las normas. Véase Las piezas del Derecho, págs. 123-124.

${ }^{34}$ Manuel Atienza y Juan Ruiz Manero, Las piezas del Derecho, pág. 10.
} 
el criterio de que tal cambio se encuentre razonablemente dentro del control de agente, de manera que pueda decirse que este agente tenía o podía haber tenido la intención de realizar ese cambio. Pero obsérvese que, estrictamente hablando, nuestra intención puede abarcar la realización de las condiciones preparatorias de tales cambios, pero no puede dirigirse directamente a ellos. Podemos tener la intención de intentar sacar un doce a los dados, pero no la intención de sacar un doce (salvo si hacemos trampas). Y si tengo razón en esto, estos cambios sólo pueden ser regulados por medio de normas de fin ${ }^{35}$, y no por medio de normas cuyo contenido es una acción final.

Unas palabras más sobre esto, antes de pasar a las conclusiones con las que quisiera terminar mi exposición: Identificar aquellas cosas que hacemos con nuestras acciones puede ser un error. Actuar es hacer algo, pero no siempre que hacemos algo estamos actuando. De la misma manera que no todo lo que no hacemos constituye omisiones nuestras (mientras les leo estas páginas, por ejemplo, no estoy omitiendo pasear por el Nepal), tampoco todo aquello que hacemos constituye acciones nuestras. Como escribe Jesús Mosterín, «mientras dormimos, hacemos muchas cosas: respiramos, sudamos, damos vueltas, apretamos la cabeza contra la almohada, soñamos, quizá roncamos o hablamos en voz alta o andamos sonámbulos por la habitación ${ }^{36}$. Estas cosas que hacemos dormidos no son acciones nuestras, aunque son cosas que hacemos. Lo mismo podemos decir de la producción de un cambio que está sólo parcialmente dentro del control del agente: producir ese cambio (por ejemplo, disminuir la tasa de mortalidad infantil) es algo que hacemos, y es algo que hacemos con nuestras acciones, pero no constituye una acción nuestra. Respecto a estos cambios, la pregunta apropiada ya no es «¿Cómo hacemos acciones?», sino -parafraseando a Austin- «¿Cómo hacemos cosas con acciones?».

11. En definitiva, las conclusiones de estas páginas serían las siguientes:

(1) Alchourrón y Bulygin han sostenido que el contenido de las normas es siempre una conducta o un estado de cosas resultado de una conducta. Para el último von Wright -si tal cosa existe-, el contenido de las normas es siempre un estado de cosas. A estas afirmaciones se puede oponer la conveniencia de distinguir entre normas de acción y normas de fin. Estas últimas pueden ser de dos tipos, según que el cambio o estado de cosas al que hagan referencia se encuentre totalmente dentro o parcialmente dentro del controldel agente. En el primer caso, estas normas de fin son traducibles a

\footnotetext{
${ }^{35} \mathrm{O}$ por medio de una norma que especificara todas las condiciones preparatorias de ese cambio.

${ }^{36}$ Jesús Mosterín, Racionalidad y acción humana, Alianza Editorial, 1987, pág. 142.
} 
normas de acción, pero no así en el segundo caso. Sólo en este segundo caso la distinción entre normas de acción y normas de fin es relevante.

(2) Aun suponiendo que el contenido de una norma sea una acción, esta afirmación esconde bajo una apariencia de homogeneidad una diversidad de normas: aquéllas cuyo contenido es una acción final, aquéllas cuyo contenido es una forma (o varias formas) de la acción y aquéllas cuyo contenido es una fase (o varias fases) de la acción. Estas distinciones pueden tener relevancia para el Derecho penal -cosa de lo que no hemos podido hablar aquí-. Piensen, por ejemplo, en distinciones de la dogmática penal, como la de delitos de mera actividad o delitos de resultado, o la de tentativa, delito frustrado y delito consumado. Además, junto con las normas de fin, constituyen un abanico de posibilidades para que el legislador dote de mayor o menor discrecionalidad al destinatario de las normas.

(3) En suma, la conclusión más importante, quizá la única conclusión de la que estoy seguro, es que la teoría de la acción abre un interesante campo de posibilidades para profundizar en el análisis del concepto de norma. Mostrarles esto ha sido la intención de mi ponencia; aburrirles ha sido sólo una consecuencia y, por tanto, de acuerdo con von Wright, no intencionada. 
DOXA 20 (1997) 